\title{
Modeling of Subcooled Boiling Heat Transfer to Cool Electronic Components in a Micro-Channel
}

\author{
Hasan Abbasinejad, Reza Hoseini Abardeh* \\ Mechanical Engineering Department, Amirkabir University of Technology, Tehran, Iran \\ Email: `hoseinir@aut.ac.ir
}

How to cite this paper: Abbasinejad, $\mathrm{H}$. and Hoseini Abardeh, R. (2020) Modeling of Subcooled Boiling Heat Transfer to Cool Electronic Components in a Micro-Channel. Journal of Electronics Cooling and Thermal Control, 9, 1-21.

https://doi.org/10.4236/jectc.2020.91001

Received: February 1, 2020

Accepted: March 28, 2020

Published: March 31, 2020

Copyright $\odot 2020$ by author(s) and Scientific Research Publishing Inc. This work is licensed under the Creative Commons Attribution International License (CC BY 4.0).

http://creativecommons.org/licenses/by/4.0/

\begin{abstract}
This paper aims to model a subcooled flow boiling in a vertical stainless-steel micro-channel with an upward flow in $1 \mathrm{~mm}$ diameter, $40 \mathrm{~mm}$ length and $0.325 \mathrm{~mm}$ thickness tube. Water has been considered as a working fluid. The heat flux varies from $600-750 \mathrm{~kW} \cdot \mathrm{m}^{-2}$, input velocity from $1-2 \mathrm{~m} \cdot \mathrm{s}^{-1}$, and the subcooled temperature varies from $59.6-79.6 \mathrm{~K}$. The working pressure and saturation temperature are $1 \mathrm{~atm}$ and $372.75 \mathrm{~K}$, respectively. The results show that, the flow boiling keeps the temperature of the channel wall lower and more uniform than a single-phase flow, as long as the flow boiling does not reach the dry-out point. The onset point of dry-out depends on three factors, heat flux, inlet velocity, and subcooled temperature. In addition, the dry-out occurs at a point near the channel inlet with increased heat flux and subcooled temperature. Decreasing the inlet velocity would also cause the dry-out point to shift closer to the inlet of the channel.
\end{abstract}

\section{Keywords}

Forced Boiling, Electronic Cooling, Subcooled Boiling, Dry-Out

\section{Introduction}

The amount of heat removal of electronic chips is considered as one of the challenges and limitations for shrinking the size of the electronic components. Presently, most chips and electronic circuits are cooled by fins and air fans that have limited heat transfer capabilities. Boiling heat transfer because of high heat transfer capabilities while maintaining at a constant temperature seems a solution for this obstacle. Especially if liquids of low boiling temperature could be used or take advantages of subcooled boiling condition of higher boiling temperature of water. It is well known that the latent heat of boiling is much greater than the sensible heat transferred to liquids. The corresponding heat transfer coefficients 
in boiling are much greater than the same coefficient in single-phase condition while keeping the temperature at a constant value of boiling condition. Keeping the temperature of electronic elements and circuits at a constant value would influence the service life of these components. Use of boiling heat transfer in reducing the operating temperature of the electronic components while increasing the amount of heat transfer by a significant amount with relatively small surface areas have been under considerable research in recent years. Boiling heat transfer in milli- and micro-channels constitutes numerous studies carried out in which some of them will be reviewed in the following.

Falsetti et al. [1] have experimentally studied two-phase flow boiling to cool a micro-pin fan. A $1 \mathrm{~cm}^{2}$ heated area composed of 66 rows of cylindrical in-line micro-pin fins with $50 \mu \mathrm{m}$ diameter, height of $100 \mu \mathrm{m}$, and pitch of $91.7 \mu \mathrm{m}$ have been used as micro-evaporator. The heat flux from $20-44 \mathrm{~W} \cdot \mathrm{cm}^{-2}$, the mass flux from $750-1750 \mathrm{~kg} \cdot \mathrm{m}^{-2} \cdot \mathrm{s}^{-1}$, and the dielectric refrigerant R134a have been considered as a working fluid. They reported a very stable flow boiling behavior for R134a. They found that the heat transfer coefficients are strongly depended on the vapor quality and the heat flux but slightly influenced by mass flux.

Ethanol and acetone with a boiling point of $78.4^{\circ} \mathrm{C}$ and $56^{\circ} \mathrm{C}$ respectively were used as working fluids by Radwan et al. [2] for cooling concentrator photovoltaic cells and electronic chips in 3D-printed monolithic double-layer microchannel heat sink in counter and parallel flow numerically. Heat flux of $1-9.2 \mathrm{~kW} \cdot \mathrm{m}^{-2}$ has been considered. Their findings indicate that the counter flow operation of forced convective boiling achieved temperature uniformity as low as $1.6^{\circ} \mathrm{C}$ and $1.8^{\circ} \mathrm{C}$ with the velocity range of $25-100 \mathrm{ml} \cdot \mathrm{h}^{-1}$ for ethanol and $50-300 \mathrm{ml} \cdot \mathrm{h}^{-1}$ for acetone, respectively.

Forced boiling heat transfer in horizontal and vertical mini-channels with upward flow have been experimentally investigated by Saisorn et al. [3]. Channel with $1.7 \mathrm{~mm}$ diameter and length of $600 \mathrm{~mm}$ was used as a test section with mass flow rate of $200-1000 \mathrm{~kg} \cdot \mathrm{m}^{-2} \cdot \mathrm{s}^{-1}$, a heat flux ranging from $1-80 \mathrm{~kW} \cdot \mathrm{m}^{-2}$ and saturation pressure of $7-13$ bar have been examined. They reported that the heat transfer coefficient depends on flow pattern as well as direction of the flow.

The effects of channel dimension, heat flux, and the flow rate on flow boiling regimes in micro-channels have been experimentally investigated by Harirchian and Garimella [4]. In their work, Fluorinert FC-77a, perfluorinated dielectric fluid, have been used as a working fluid with mass flux ranging from 225 - 1420 $\mathrm{kg} \cdot \mathrm{m}^{-2} \cdot \mathrm{s}^{-1}$. Channel width ranging from $100-5850 \mu \mathrm{m}$, and all with a depth of $400 \mu \mathrm{m}$ and a length of $12.7 \mathrm{~mm}$ have been considered. They reported that flow pattern for micro-channel of $400 \mu \mathrm{m}$ depth and larger are similar and nucleate boiling is dominated. However, flow patterns in smaller channels differ from those of $400 \mu \mathrm{m}$ depth and bubble nucleation at the wall is suppressed. In addition, their results show that as channel width increases, bubble flow replaces by slug flow and intermittent churn/wispy-annular flow replaces intermittent churn/annular 
flow. Furthermore, for microchannel of $400 \mu \mathrm{m}$ and larger the heat transfer coefficient is almost independent of the channel size.

Ong and Thome [5] have investigated the flow boiling of R134a, R236fa, and R245fa in a horizontal circular channel with a diameter of $1.030 \mathrm{~mm}$. This study was performed with a heat flux range of $2.3-250 \mathrm{~kW} \cdot \mathrm{m}^{-2}$, mass flux range of 200 - $1600 \mathrm{~kg} \cdot \mathrm{m}^{-2} \cdot \mathrm{s}^{-1}$, and a subcooled temperature range of $2-9 \mathrm{~K}$ at a saturation temperature of $31^{\circ} \mathrm{C}$. A correlation between the boiling heat transfer coefficients, the mass flow rate and heat fluxes have been presented. They reported that the subcooled temperature did not affect the heat transfer coefficient.

Owhib et al. [6] conducted an experimental work on saturated flow boiling in microchannels. They have measured the heat transfer coefficients for saturated boiling of R134a in vertical channels with internal diameters of 1.7, 1.224, and $0.826 \mathrm{~mm}$. A uniformly heated length of $220 \mathrm{~mm}$, with a mass flow rate ranging from $50-400 \mathrm{~kg} \cdot \mathrm{m}^{-2} \cdot \mathrm{s}^{-1}$, and the heat flux ranging from $3-34 \mathrm{~kW} \cdot \mathrm{m}^{-2}$ with two different pressures of 8.626 and 6.458 bar have been investigated. Their results show that the heat transfer coefficient is a strong function of the heat flux and system pressure, while it is almost independent of mass flux and vapor quality.

Yu et al. [7] have examined the boiling heat transfer of water in a small-diameter horizontal tube with an inner diameter of $2.98 \mathrm{~mm}$ and a heated length of 0.91 $\mathrm{m}$. mass flux in a range of $50-200 \mathrm{~kg} \cdot \mathrm{m}^{-2} \cdot \mathrm{s}^{-1}$, inlet temperature from ambient to $80^{\circ} \mathrm{C}$, and a system pressure of $200 \mathrm{Kpa}$ have been considered. Their findings suggest that the heat transfer coefficients and pressure drop for this channel differ from those in wider channels. In addition, the boiling heat transfer depends on heat flux and independent of mass flow rate.

The numerical and experimental study of Zhang et al. [8] indicates a very good agreement between their results. The flow boiling in rectangular channels with hydraulic diameters between $25-60 \mu \mathrm{m}$ and aspect ratios 1 to 3.5 have been considered.

Hosseini et al. [9] [10] in two separate experimental studies, performed investigation on the effect of material and roughness of the surfaces on pool boiling heat transfer of refrigerant R113 on horizontal circular plates of brass, copper and aluminum. The aim of the research was to study pool boiling in a small volume of R113 for possible use in electronic cooling. The experiments were carried out for the heat flux of $8-200 \mathrm{~kW} \cdot \mathrm{m}^{-2}$. The heat transfer coefficients were calculated by measuring wall superheat of the samples and the input heat flux. The obtained results have shown significant effect of surface material, with copper providing the highest heat transfer coefficient among the samples, and aluminum the least. Concerning the roughness effect, the results show significant improvement of the heat transfer coefficient as the surface roughness is increased. The samples were treated by different sand paper grit sizes to achieve different surface roughness $(\mathrm{Ra})$. It was found that the heat transfer coefficient of the sample with $\mathrm{Ra}=0.901$ is $3.4 \%, 10.5 \%$, and $38.5 \%$ higher in comparison with surfaces with $\mathrm{Ra}$ of $0.735,0.65$, and 0.09 respectively at heat flux of $170 \mathrm{~kW} \cdot \mathrm{m}^{-2}$. 
As mentioned above, the boiling heat transfer mechanism would be one of the possible solution for increasing the amount of heat removal from electronic components and integrated circuits. An obstacle presently exists in reducing the size of the electronic components. This implies more serious studies about this mechanism and parameters affecting the process, especially in milli- and micro-channels. The main aim of the present work therefore is, investigation of the flow boiling in a stainless steel microchannel with a diameter of $1 \mathrm{~mm}$, length of $40 \mathrm{~mm}$, and a thickness of $0.325 \mathrm{~mm}$. The heat applied to the channel wall is considered equivalent to the heat generated by all electronic components exists in a chip or integrated circuit. Of course, in order to get better understanding on how the boiling heat transfer affects the temperature of the channel wall, a comparison will be made between single-phase and two-phase flow boiling. The parameters affecting the mechanism of the boiling heat transfer and the dry-out phenomenon on the flow boiling and heat transfer will be addressed in next sections.

\section{Governing Equations}

The Eulerian-Eulerian model in the fluent code was used to model the flow field and boiling process. Equations for each phase (liquid and vapor) are presented and solved separately. The Rensselaer Polytechnic Institute (RPI) model is also applied for boiling on the channel wall.

\subsection{Continuity Equations}

In the Eulerian multiphase boiling model, the continuity equation is defined as follow [11] [12]:

$$
\frac{\partial}{\partial t}\left(\alpha_{q} \rho_{q}\right)+\nabla \cdot\left(\alpha_{q} \rho_{q} v_{q}\right)=\sum_{p=1}^{n}\left(\dot{m}_{p q}-\dot{m}_{q p}\right)+S_{q} .
$$

where $v_{q}$ is the phase velocity, $\dot{m}_{p q}$ is mass transfer from $p^{\text {th }}$ to $q^{\text {th }}$ phase, $\dot{m}_{q p}$ is mass transfer from $q^{\text {th }}$ to $p^{\text {th }}$ phase, and $S_{q}$ is an external mass source on the $q^{\text {th }}$ phase that here has been considered 0 [11] [12].

\subsection{Momentum Equation}

The momentum equation is given by [12]

$$
\begin{gathered}
\frac{\partial}{\partial t}\left(\alpha_{q} \rho_{q} \boldsymbol{v}_{q}\right)+\nabla \cdot\left(\alpha_{q} \rho_{q} \boldsymbol{v}_{q} \boldsymbol{v}_{q}\right)=-\alpha_{q} \nabla p+\nabla \cdot \overline{\bar{\tau}}_{q}+\alpha_{q} \rho_{q} \boldsymbol{g} \\
\sum_{p=1}^{n}\left(\boldsymbol{R}_{p q}+\dot{m}_{p q} \boldsymbol{v}_{p q}-\dot{m}_{q p} \boldsymbol{v}_{q p}\right)+\left(\boldsymbol{F}_{q}+\boldsymbol{F}_{l i f t, q}+\boldsymbol{F}_{w l, q}+\boldsymbol{F}_{v m, q}+\boldsymbol{F}_{t d, q}\right)
\end{gathered}
$$

where $\boldsymbol{F}_{q}$ is external body force, $\boldsymbol{F}_{l i f t, q}$ is lift force, $\boldsymbol{F}_{w l, q}$ is wall lubrication force, $\boldsymbol{F}_{v m, q}$ virtual mass exchange force, and $\boldsymbol{F}_{t d, q}$ is a turbulent dispersed force, and $\boldsymbol{R}_{p q}$ is the interaction drag force between the two-phases.

$$
\overline{\bar{\tau}}_{q}=\alpha_{q} \mu_{q}\left(\nabla \boldsymbol{v}_{q}+\nabla \boldsymbol{v}_{q}^{\mathrm{T}}\right)+\alpha_{q}\left(\lambda_{q}-\frac{2}{3} \mu_{q}\right) \nabla \cdot \boldsymbol{v}_{q} \overline{\bar{I}}
$$


where $\overline{\bar{\tau}}_{q}, \mu_{q}$ and $\lambda_{q}$ are shear stress tensor, shear viscosity and bulk viscosity of $q^{\text {th }}$ phase, respectively.

\subsection{Energy Equation}

The energy equation is expressed as follows [12]:

$$
\begin{aligned}
& \frac{\partial}{\partial t}\left(\alpha_{q} \rho_{q} h_{q}\right)+\nabla \cdot\left(\alpha_{q} \rho_{q} \boldsymbol{v}_{q} h_{q}\right) \\
& =\alpha_{q} \frac{\partial p_{q}}{\partial t}+\overline{\bar{\tau}}_{q}: \nabla \boldsymbol{v}_{q}-\nabla \cdot \boldsymbol{q}_{q}+\sum_{p=1}^{n}\left(Q_{p q}+\dot{m}_{p q} h_{p q}-\dot{m}_{q p} h_{q p}\right)+S_{q}
\end{aligned}
$$

where $h_{q}, \boldsymbol{q}_{q}$ and $S_{q}$ are specific enthalpy, heat flux and an external heat source of $q^{\text {th }}$ phase, respectively. $Q_{p q}$ and $h_{p q}$ are heat transfer and enthalpy between $p^{\text {th }}$ and $q^{\text {th }}$ phases, respectively.

\subsection{Turbulence Model Equation}

In this study, turbulence $\kappa-\varepsilon$ model has been used for the mixture; these two parameters are expressed as following [12]:

$$
\begin{gathered}
\frac{\partial}{\partial t}\left(\rho_{m} k\right)+\nabla \cdot\left(\rho_{m} \boldsymbol{v}_{m} k\right)=\nabla \cdot\left(\left(\mu_{m}+\frac{\mu_{t, m}}{\sigma_{k}}\right) \nabla k\right)+G_{k, m}-\rho_{m} \varepsilon+\Pi_{k_{m}} \\
\frac{\partial}{\partial t}\left(\rho_{m} \varepsilon\right)+\nabla \cdot\left(\rho_{m} v_{m} \varepsilon\right)=\nabla \cdot\left(\left(\mu_{m}+\frac{\mu_{t, m}}{\sigma_{\varepsilon}}\right) \nabla \varepsilon\right)+\frac{\varepsilon}{k}\left(C_{1 \varepsilon} G_{k, m}-C_{2 \varepsilon} \rho_{m} \varepsilon\right)+\Pi_{\varepsilon_{m}}
\end{gathered}
$$

where the density, molecular viscosity, and velocity are given by Equations (7) to (9):

$$
\begin{array}{r}
\rho_{m}=\sum_{i=1}^{N} \alpha_{i} \rho_{i} \\
\mu_{m}=\sum_{i=1}^{N} \alpha_{i} \mu_{i} \\
\boldsymbol{v}_{m}=\frac{\sum_{i=1}^{N} \alpha_{i} \rho_{i} \boldsymbol{v}_{i}}{\sum_{i=1}^{N} \alpha_{i} \rho_{i}}
\end{array}
$$

The turbulence viscosity and turbulence kinetic energy are defined by the following Equations (10) and (11) respectively:

$$
\begin{gathered}
\mu_{t, m}=\rho_{m} C_{\mu} \frac{k^{2}}{\varepsilon} \\
G_{k, m}=\mu_{t, m}\left(\nabla \boldsymbol{v}_{m}+\left(\nabla \boldsymbol{v}_{m}\right)^{\mathrm{T}}\right): \nabla \boldsymbol{v}_{m}
\end{gathered}
$$

The terms $\Pi_{k_{m}}$ and $\Pi_{\varepsilon_{m}}$ in Equations (5) and (6) relate the turbulence interactions between the dispersed and continues phases of the flow. In this modeling, the values of constant coefficients are assumed equal to those of the used software. 


\subsection{Equations Governing RPI Model}

According to the RPI model, a well-known model developed by Kurul \& Podowski [13], the total heat flux transferred from the wall to the fluid mixture includes three parts: the convective heat flux $\left(\dot{q}_{C}\right)$, the quenching heat flux $\left(\dot{q}_{Q}\right)$, and the evaporation heat flux $\left(\dot{q}_{E}\right)$ :

$$
\dot{q}_{W}=\dot{q}_{C}+\dot{q}_{Q}+\dot{q}_{E}
$$

where convective heat flux is shown in Equation (13):

$$
\dot{q}_{C}=h_{c}\left(T_{w}-T_{l}\right)\left(1-A_{b}\right)
$$

In Equation (13), $h_{c}$ is the liquid phase heat transfer coefficient, $A_{b}$ is the influence area, $T_{w}$ and $T_{l}$ are the wall and the liquid temperature, respectively.

Quenching heat flux is defined in Equation (14):

$$
\dot{q}_{Q}=\frac{2 k_{l}}{\sqrt{\frac{\pi \lambda_{l}}{f_{b w}}}}\left(T_{w}-T_{l}\right)
$$

where $k_{l}$ is the thermal conductivity, $f_{b w}$ is the frequency of bubble departure and $\lambda_{l}=\frac{k_{l}}{\rho_{l} C_{p l}}$ is the liquid phase diffusion coefficient.

Evaporation heat flux is defined in Equation (15):

$$
\dot{q}_{E}=\frac{\pi}{6} d_{b w}^{3} f_{b w} N_{w} \rho_{v} h_{l v}
$$

In Equation (15), $d_{b w}, N_{w}, \rho_{v}, h_{l v}$ are bubble departure diameter, active nucleate site density, density of the vapor phase, and latent heat of evaporation, respectively.

The parameters required in Equations (13) to (15) are defined below:

The Influence area in Equation (13) is defined in Equation (16):

$$
A_{b}=\min \left(1, k \frac{N_{w} \pi d_{b w}^{2}}{4}\right)
$$

where $k$, is the empirical coefficient and is determined by the relation suggested by Del Valle and Kenning [14] as given in Equation (17):

$$
k=4.8 \mathrm{e}^{-\frac{J a_{\text {sub }}}{80}}
$$

where $J a_{\text {sub }}$ is the subcooled Jacob number given by Equation (18):

$$
J a_{\text {sub }}=\frac{\rho_{l} C_{p l} \Delta T_{\text {sub }}}{\rho_{v} h_{l v}}
$$

where $\Delta T_{\text {sub }}=T_{\text {sat }}-T_{l}$.

The frequency of Bubble departure is defined in Equation (19) based on the model developed by Cole [15]:

$$
f_{b w}=\frac{1}{T}=\sqrt{\frac{4 g\left(\rho_{l}-\rho_{v}\right)}{3 \rho_{l} d_{b w}}}
$$


Bubble departure diameter is calculated from Equation (20) based on the model developed by Tolubinski-Kostanchuk [16]:

$$
d_{b w}=\min \left(0.0014,0.0006 \exp \left(-\frac{\Delta T_{\text {sub }}}{45}\right)\right)
$$

Active nucleate site density is calculated from Equation (21).

$$
N_{w}=C^{n}\left(T_{w}-T_{s a t}\right)^{n}
$$

where $n=1.805$ and $C=210$ based on Lemmert-Chawla correlation [17]:

Other relations for active nucleate site density provided by Kocamustafaogullari and Ishii [18] as shown in Equation (22):

$$
N_{w}^{*}=f\left(\rho^{*}\right) r_{c}^{*-4.4}
$$

where

$$
\begin{aligned}
& N_{w}^{*}=N_{w} d_{b w}^{2} \\
& r_{c}^{*}=\frac{2 r_{c}}{d_{b w}} \\
& r_{c}=\frac{2 \sigma T_{s a t}}{\rho_{v} h_{l v}\left(T_{w}-T_{s a t}\right)} \\
& \rho^{*}=\frac{\rho_{l}-\rho_{v}}{\rho_{v}}
\end{aligned}
$$

The density function in Equation (22) is calculated from Equation (23):

$$
f\left(\rho^{*}\right)=2.157 \times 10^{-7} \rho^{*-3.2}\left(1+0.0049 \rho^{*}\right)^{4.13}
$$

According to the base model of RPI, the vapor temperature is assumed constant and equal to the saturation temperature. The vapor temperature and the amount of heat transferred are needed in the solution process in order to model non-equilibrium boiling and critical heat flux (CHF). The modified RPI relation to contain a term for the diffusive heat flux of the vapor phase $\dot{q}_{V}$ and the heat flux to any other possible gas phases $\dot{q}_{G}$, is given in Equation (24):

$$
\dot{q}_{W}=\left(\dot{q}_{C}+\dot{q}_{Q}+\dot{q}_{E}\right) f\left(\alpha_{1}\right)+\left(1-f\left(\alpha_{1}\right)\right) \dot{q}_{V}+\dot{q}_{G}
$$

$\dot{q}_{V}$ and $\dot{q}_{G}$ are given in Equations (25) and (26) according to [12]:

$$
\begin{aligned}
& \dot{q}_{V}=h_{V}\left(T_{W}-T_{V}\right) \\
& \dot{q}_{G}=h_{G}\left(T_{W}-T_{G}\right)
\end{aligned}
$$

The function $f\left(\alpha_{l}\right)$ in Equation (24) depends on the local liquid/vapor volume fraction that can be calculated by the relation proposed by Loilev et al. [19]:

$$
f\left(\alpha_{v}\right)=1-f\left(\alpha_{l}\right)=\max \left(0, \min \left\{1, \frac{\alpha_{v}-\alpha_{v, 1}}{\alpha_{v, 2}-\alpha_{v, 1}}\right\}\right)
$$

where the breakpoints have been set to $\alpha_{v, 1}=0.9$ and $\alpha_{v, 2}=0.95$. 


\section{Problem Statement and Boundary Conditions}

In this work, the subcooled boiling heat transfer is investigated in a vertical microchannel with an upward flow in $1 \mathrm{~mm}$ diameter channel with $40 \mathrm{~mm}$ length and stainless-steel material. The thickness of the channel is $0.325 \mathrm{~mm}$. Figure 1 provides a schematic representation of a solution domain. Here, the boundary conditions are; constant subcooled temperature, constant velocity for the inlet flow and constant heat flux applied on the channel wall. The inlet velocity ranging from $1-2 \mathrm{~m} \cdot \mathrm{s}^{-1}$, inlet subcooled temperature of $59.6-79.6 \mathrm{~K}$, and heat flux in the range of $600-750 \mathrm{~kW} \cdot \mathrm{m}^{-2}$. Water was used as a working fluid at a pressure of 1 bar and saturation temperature of $372.75 \mathrm{~K}$. The thermophysical properties of stainless steel and water in the two liquid and vapor phases at the different inlet and saturation temperatures are provided in Table 1.

\section{Modeling}

First of all, modeling was performed in the single-phase flow without applying the energy equation; a velocity profile obtained from this single-phase flow was applied as a boundary condition for boiling flow. Then, enable the energy equation and take Eulerian model to simulate boiling heat transfer. Non-equilibrium

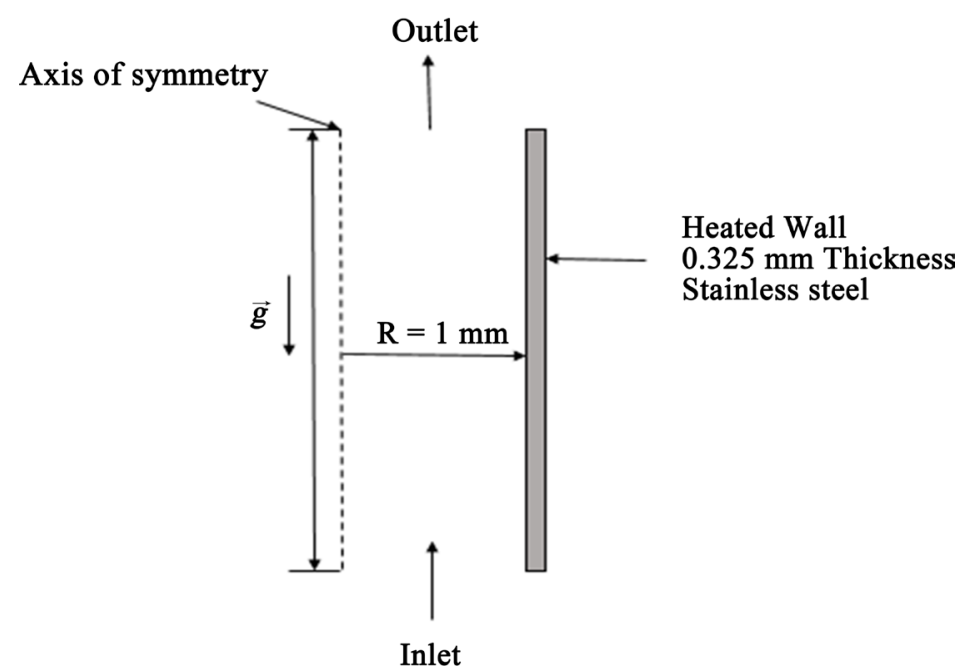

Figure 1. A schematic representation of solution domain.

Table 1. Thermophysical properties of stainless steel and water at a pressure of 1 bar [20].

\begin{tabular}{ccccc}
\hline Material & $\begin{array}{c}\boldsymbol{\rho} \\
\left(\mathrm{kg} / \mathrm{m}^{3}\right)\end{array}$ & $\begin{array}{c}C_{p} \\
(\mathrm{~J} /(\mathrm{kg} \cdot \mathrm{K}))\end{array}$ & $\begin{array}{c}K \\
(\mathrm{~W} /(\mathrm{m} \cdot \mathrm{K}))\end{array}$ & $\begin{array}{c}\boldsymbol{\mu} \\
(\mathrm{kg} /(\mathbf{m} \cdot \mathbf{s}))\end{array}$ \\
\hline Water $(T=293.15 \mathrm{~K})$ & 998.2 & 4185 & 0.5985 & 0.0001001 \\
Water $(T=303.15 \mathrm{~K})$ & 995.6 & 4180 & 0.6155 & 0.000797 \\
Water $(T=313.15 \mathrm{~K})$ & 992.2 & 4178 & 0.631 & 0.000653 \\
Liquid Water $(T=372.75 \mathrm{~K})$ & 958.64 & 4216 & 0.679 & 0.0002829 \\
Vapor Water $(T=372.75 \mathrm{~K})$ & 0.59 & 2076 & 0.025 & 0.000012256 \\
stainless steel & 8030 & 502.48 & 16.27 & - \\
\hline
\end{tabular}


model has been applied to calculate the temperature of the vapor. The change in the thermophysical properties of the fluid due to the change in temperature was considered linear, and modeling was performed in a two-dimensional, steady state and no-slip boundary condition for two phases. Coupled algorithm (pressure based coupled algorithm) has been used for pressure-velocity coupling. Constants temperature at inlet and constant heat flux on wall channel have been use as boundary conditions. The $\kappa-\varepsilon$ model was used for turbulence. It should be noted that because of symmetry, a half channel was simulated to reduce the computational time.

\section{Validation and Grid-Independence}

For validation of the two-phase flow modeling, the experimental work of Owhaib et al. [6] first was modeled and the results obtained were then compared with their given experimental findings. The information of experimental work of Owhaib et al. [6] on the flow boiling in the vertical microchannel are presented in Table 2. Figure 2 and Figure 3 represent the modeling and the experimental results for two channels with diameters of 1.224 and $0.826 \mathrm{~mm}$, respectively. Based on these figures, the results from modeling are reasonably comparable to those of experimental outcome. Table 3 provides the value of error for modeling and Owhaib et al. experimental findings. The maximum error is $17.39 \%$, and the minimum error is $1.85 \%$.

Two mesh sizes $\left(15^{*} 521\right)$ and $\left(25^{*} 869\right)$ have been used in order to examine the grid dependent results. Figure 4 presents the wall temperature of the channel at outlet position for these two mesh sizes. According to Figure 4, it is clear that

Table 2. Experimental conditions of Owhaib et al. [6] used for modeling.

\begin{tabular}{cccccc}
\hline Fluid & Channel diameter $(\mathrm{mm})$ & $q\left(\mathrm{~kW} / \mathrm{m}^{2}\right)$ & $G\left(\mathrm{~kg} /\left(\mathrm{m}^{2} \cdot \mathrm{s}\right)\right)$ & $T_{\text {sat }}\left({ }^{\circ} \mathrm{C}\right)$ & $T_{\text {in }}\left({ }^{\circ} \mathrm{C}\right)$ \\
\hline Water & $1.224 \& 0.826$ & $10-35$ & $300 \& 400$ & 34 & 34 \\
\hline
\end{tabular}

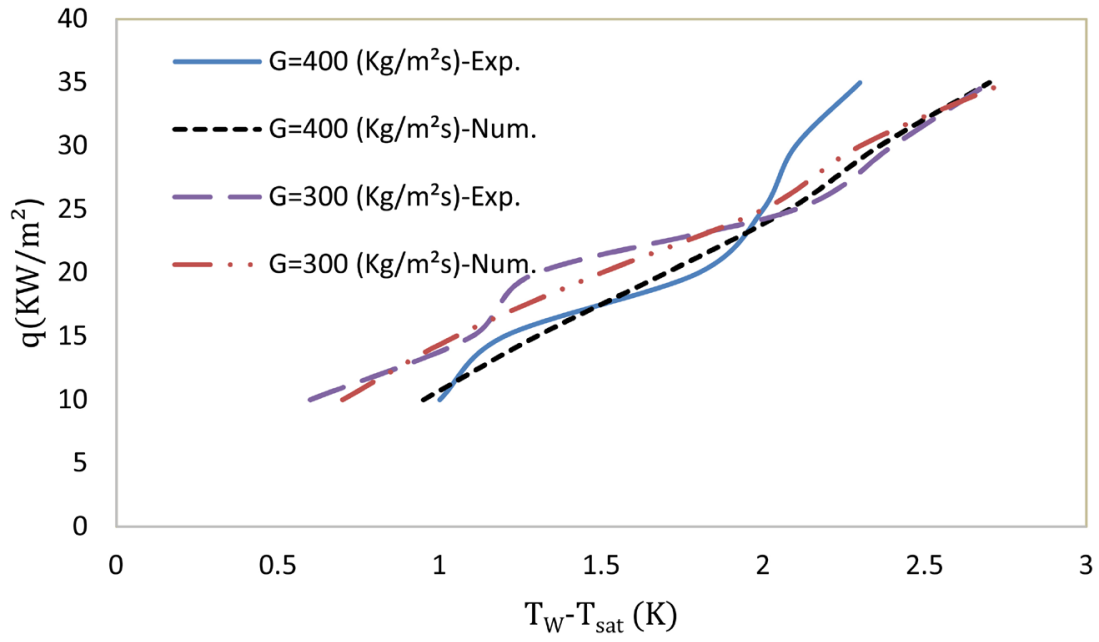

Figure 2. Results of modeling and Owhaib et al. [6] experimental work of flow boiling in $1.224 \mathrm{~mm}$ diameter microchannel. 


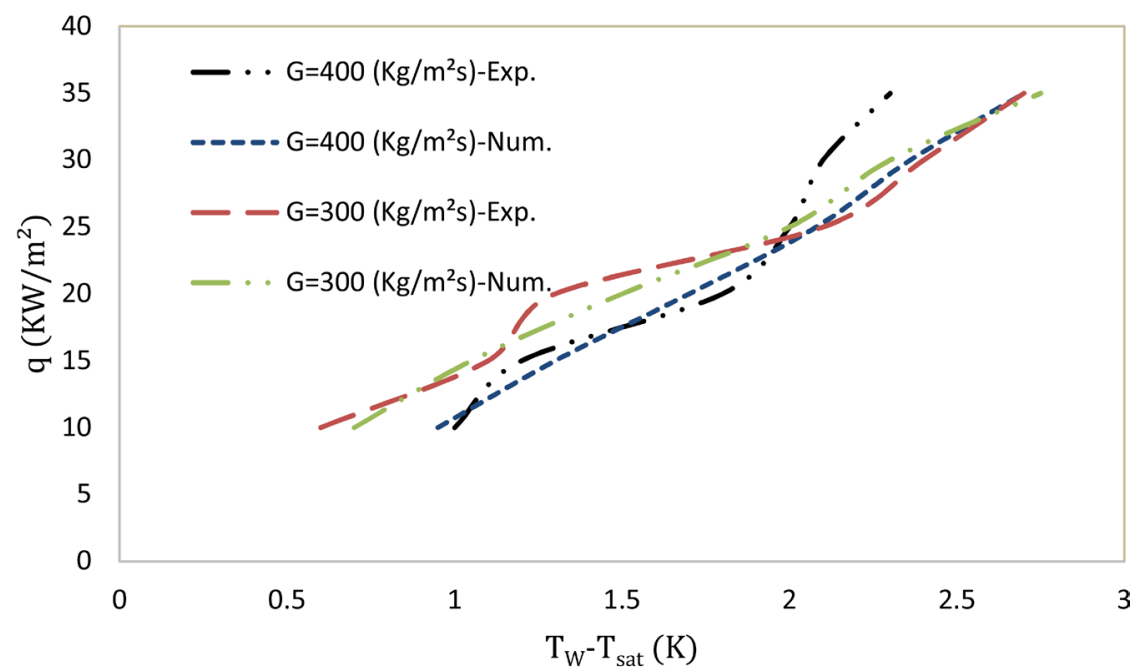

Figure 3. Results of modeling and Owhaib et al. [6] experimental work of flow boiling in $0.826 \mathrm{~mm}$ diameter microchannel.

Table 3. Percentage of error of the wall temperature differences between experimental and modeling results $\left|\frac{T_{\text {exp }}-T_{\text {num }}}{T_{\text {exp }}}\right| \times 100$.

\begin{tabular}{cccccc}
\hline & Diameter $(\mathrm{mm})$ & \multicolumn{2}{c}{$\boldsymbol{d}=\mathbf{0 . 8 2 6}$} & \multicolumn{2}{c}{$\boldsymbol{d}=\mathbf{1 . 2 2 4}$} \\
\hline & Mass Flux $\left(\mathrm{kg} /\left(\mathrm{m}^{2} \cdot \mathrm{s}\right)\right)$ & $\mathbf{3 0 0}$ & 400 & 300 & 400 \\
\hline 10 & $16.66 \%$ & $5 \%$ & $5.38 \%$ & $10 \%$ \\
& 15 & $4.54 \%$ & $8.33 \%$ & $10.47 \%$ & $10.52 \%$ \\
$\begin{array}{c}\text { Heat Flux } \\
\left(\mathrm{kW} / \mathrm{m}^{2}\right)\end{array}$ & 20 & $15.38 \%$ & $5.55 \%$ & $4.16 \%$ & $12 \%$ \\
& 25 & $4.76 \%$ & $4 \%$ & $7.93 \%$ & $10.34 \%$ \\
& 30 & $4.16 \%$ & $12.38 \%$ & $11.7 \%$ & $9.37 \%$ \\
& 35 & $1.85 \%$ & $17.39 \%$ & $9.16 \%$ & $5.88 \%$ \\
\hline
\end{tabular}

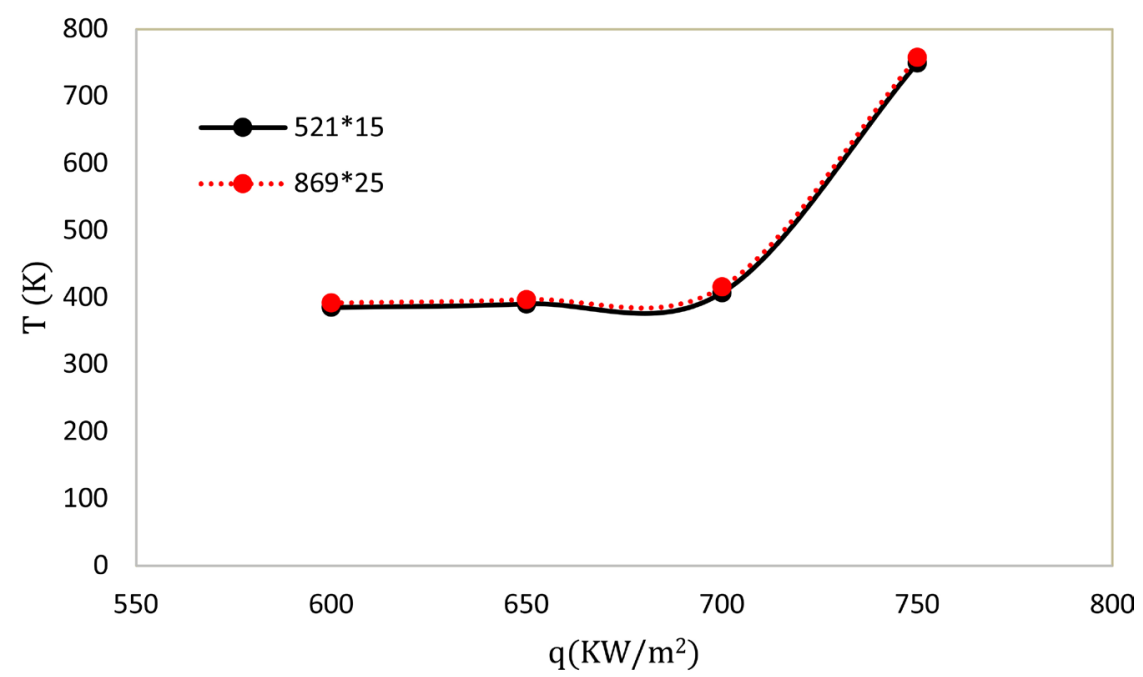

Figure 4. Examination of the mesh sizing on wall temperature of the channel at outlet position. 
the mesh size does not affect the modeling results, so that it can be claimed that the obtained result is independent of the mesh sizing. Therefore, a mesh size of $(15 * 521)$ will be used in remaining part of this study.

\section{Results}

The results will be shown in this section. First, the superiority of the flow boiling for cooling of the electronic components over a single phase heat transfer will be addressed. Since the dry-out phenomenon has a severe impact on the flow boiling heat transfer, it will be addressed next. The results considered here are for the velocity in the range of $1-2 \mathrm{~m} \cdot \mathrm{s}^{-1}$, subcooled temperature in the range of $59.6-79.6 \mathrm{~K}$, and heat flux in the range of $600-750 \mathrm{~kW} \cdot \mathrm{m}^{-2}$.

Figure 5(a) presents the variation of the temperature of the inner wall of the channel for four different heat fluxes of $600,650,700$ and $750 \mathrm{~kW} \cdot \mathrm{m}^{-2}$ in both single-phase and two-phase flows. The inlet velocity of fluid is $V_{\text {Inlet }}=1 \mathrm{~m} \cdot \mathrm{s}^{-1}$ and the subcooled temperature is $\Delta T_{\text {sub }}=69.6 \mathrm{~K}$. Figure $5(\mathrm{a})$ shows that, the temperatures of the inner wall in the two-phase flow are lower than that of a single-phase

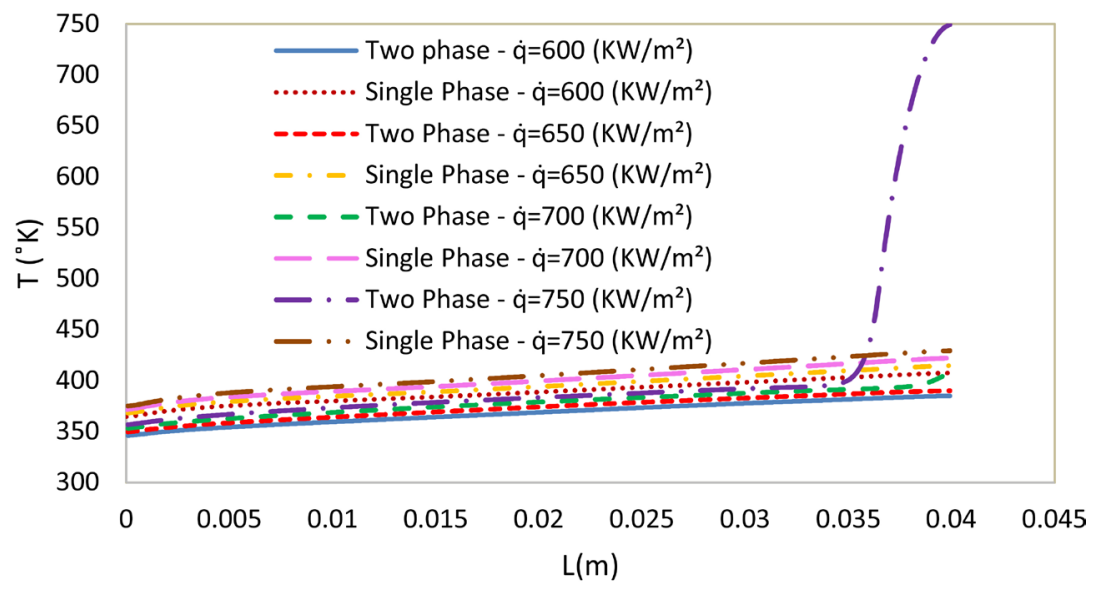

(a)

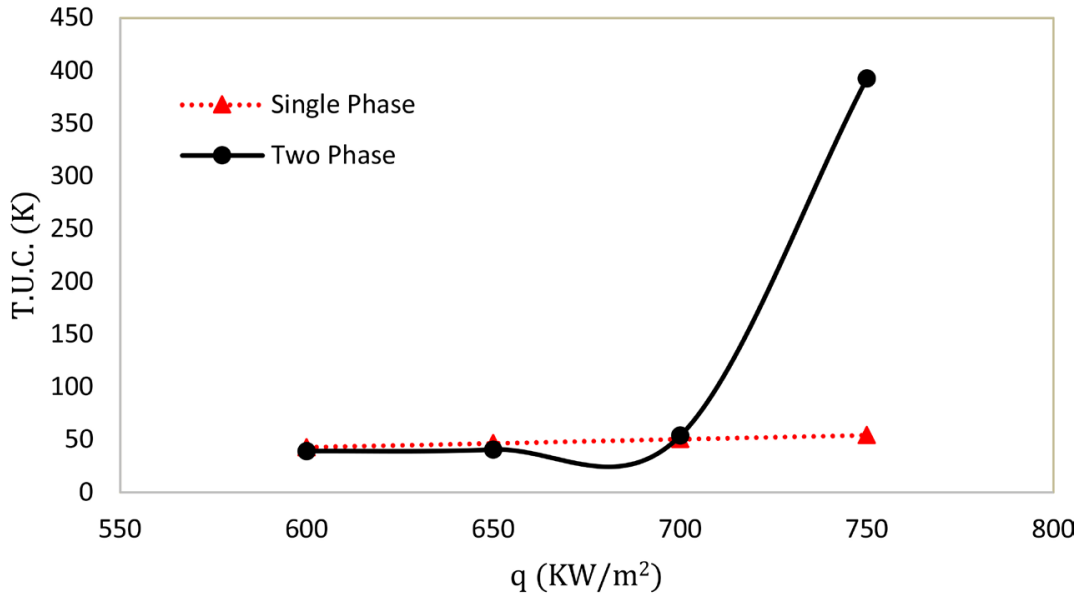

(b)

Figure 5. The effect of heat flux at single-phase and two-phase (boiling) flows on (a) inner wall temperature, (b) T.U.C. 
from inlet to outlet. A sudden increase in temperature of the wall observed as the heat flux reaches to $700 \mathrm{~kW} \cdot \mathrm{m}^{-2}$ and over, indicates a severe decrease in the heat transfer coefficients due to the dry-out. It is well known that, the life times of the electronic components are dependent strongly on their operating temperatures. According to Figure 5(a), the temperature at the end of the channel in single-phase flow is $5.5 \%, 6 \%$, and $4 \%$ more than that of the corresponding two-phase flow for heat fluxes of 600,650 , and $700 \mathrm{~kW} \cdot \mathrm{m}^{-2}$, respectively. However, in the case of heat flux of $750 \mathrm{~kW} \cdot \mathrm{m}^{-2}$, the temperature at the end of the channel in two-phase flow is $74.5 \%$ higher than that of single-phase flow, because of entering to the dry-out condition. Therefore, if the operating temperatures can be controlled at lower range by use of the flow boiling as indicated in Figure 5(a) it is possible to increase the life time of electronic components. However, it should be noted that the flow-boiling regime should be away from the dry-out condition to avoid temperature jump. Figure 5(b) presents the temperature uniformity coefficient (T.U.C.) which is defined as the maximum deviation of temperature along the channel wall. According to this figure, in the boiling phase, before reaching the dry-out point, T.U.C. is less. In fact, the surface temperature of the channel is less varied in the boiling phase, which can affect positively the service life of electronic components.

Figure 6(a) shows the wall temperature at different subcooled temperatures, fluid inlet velocity is $V_{\text {Inlet }}=1 \mathrm{~m} \cdot \mathrm{s}^{-1}$ and applied heat flux is $q=610 \mathrm{~kW} \cdot \mathrm{m}^{-2}$. As Figure 6(a) shows, before reaching the dry-out point, the wall temperature all over the length of the channel in the flow boiling condition is lower than that of the single-phase flow. Although the variation of the subcooled temperature do not significantly affect the wall temperature in a single-phase flow, it is clear that the wall temperature will increase as the subcooled temperature decreases in the flow boiling. By decreasing subcooled temperature from $79.6 \mathrm{~K}$ to $69.6 \mathrm{~K}$, the wall temperature at the end of the channel rises by $2.1 \%$. Figure $6(\mathrm{~b})$ indicates that T.U.C. in the two-phase flow (boiling), before dry-out point is lower than that of single-phase flow. In the case of dry-out, the temperature difference increases considerably.

With respect to the above results, it is clear that in the flow boiling and away from dry-out point, the wall temperature and its variation is lower than single-phase flow. Accordingly, the flow boiling in microchannel for electronic components cooling is suggested. In the following subsections, the results of the investigated effects of the heat flux, subcooled temperature, and inlet velocity on the flow boiling inside the microchannel will be fully reported.

\subsection{Effect of Heat Flux on Flow Boiling Heat Transfer}

The amount of heat flux applied to the channel wall is one of the parameters influencing the heat transfer coefficients. To study this issue, the heat flux applied to the channel were changed from $650-750 \mathrm{~kW} \cdot \mathrm{m}^{-2}$, while the inlet velocity and subcooled temperature remain constant at $1 \mathrm{~m} \cdot \mathrm{s}^{-1}$ and $69.6 \mathrm{~K}$, respectively. 


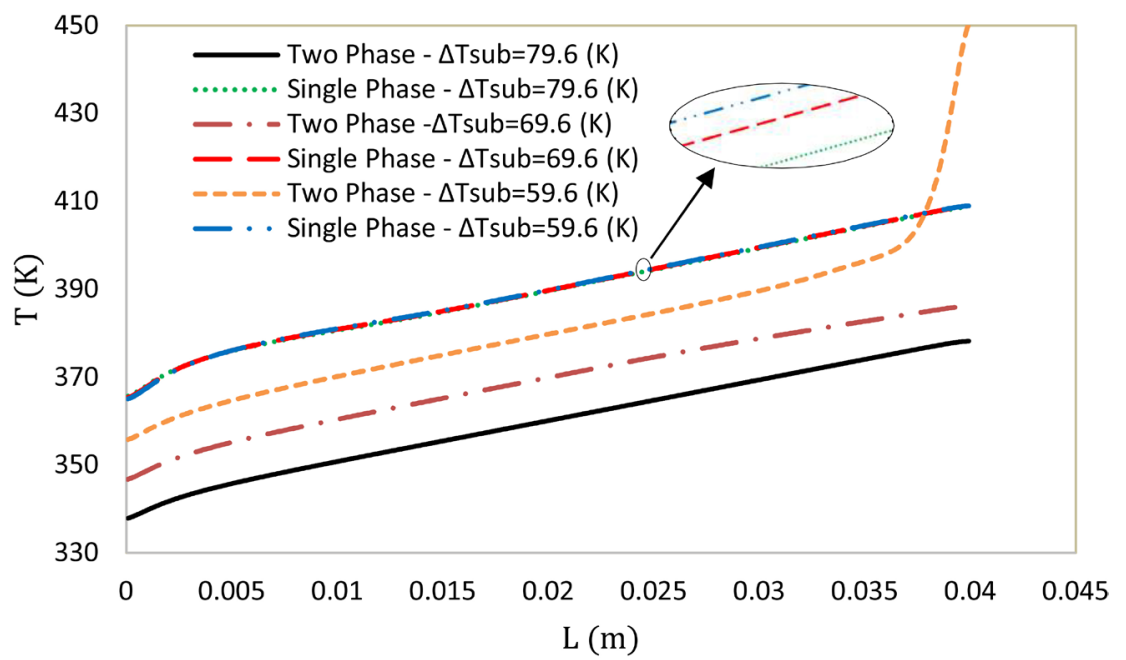

(a)

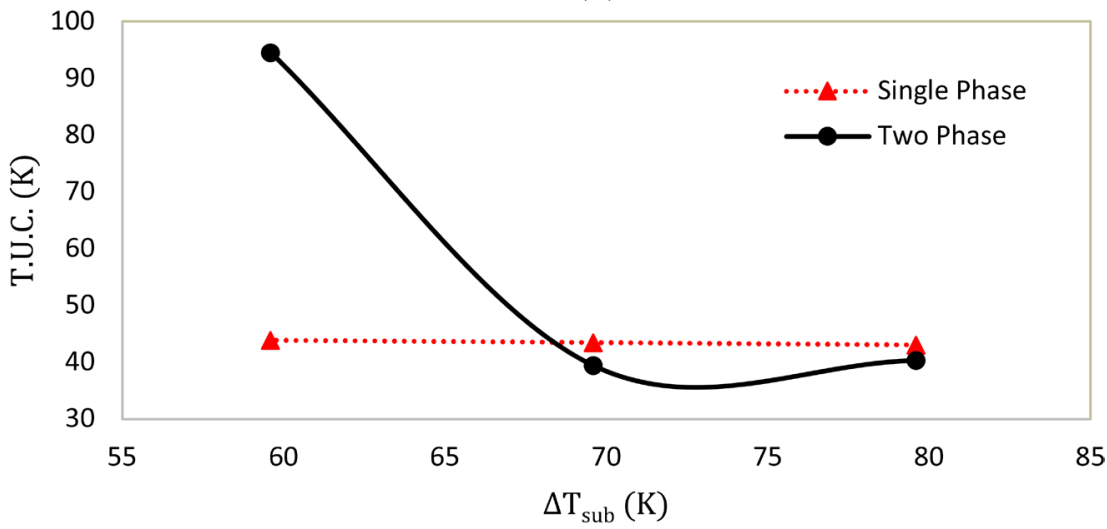

(b)

Figure 6. The effect of subcooled temperature at single-phase and two-phase (boiling) flows on (a) inner wall temperature and, (b) T.U.C.

As can be seen in Figure 7, the wall temperature will increase as the heat flux increases, while the bulk temperature, calculated by averaging the temperature of five points at $0,0.1,0.2,0.3$ and $0.4 \mathrm{~mm}$ intervals from the central axis of the channel, remains lower than the saturation temperature. This means that the heat transfer is a subcooled boiling type. When the applied heat flux approaches to $700 \mathrm{~kW} \cdot \mathrm{m}^{-2}$, a sudden increase in the wall temperature observed which is an indication of reaching to the dry-out point. The dry-out point would get closer to the channel inlet as the heat flux increases. To better represent the distribution of heat transfer, Figure 8 shows the wall heat flux partitions for $q=700 \mathrm{~kW} \cdot \mathrm{m}^{-2}$ and $q=750 \mathrm{~kW} \cdot \mathrm{m}^{-2}$. Based on this figure, after the onset of boiling, liquid single-phase heat transfer begins to decrease and on the other hand, evaporation and quenching heat transfer begins to increase. Upon reaching the dry-out point, the liquid single-phase heat transfer vanishes, because there is no longer any liquid phase near the wall, while vapor single-phase heat transfer begins to increase. However, vapor single-phase heat transfer is negligible in comparison to liquid phase heat transfer. 


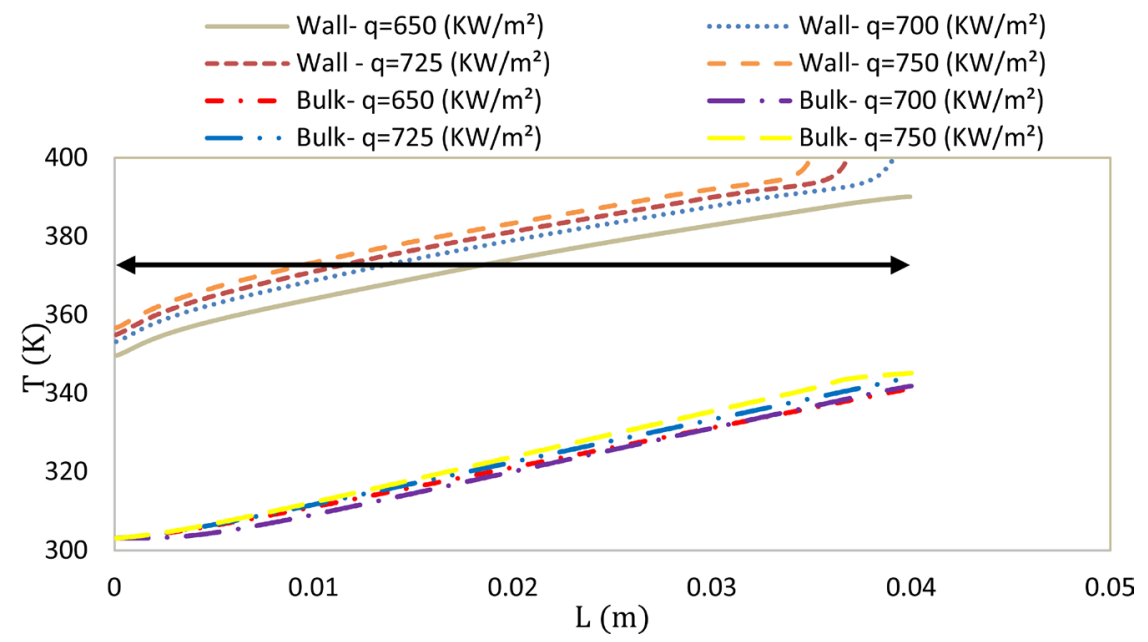

Figure 7. The effect of heat flux on inner wall and bulk temperature along the channel.

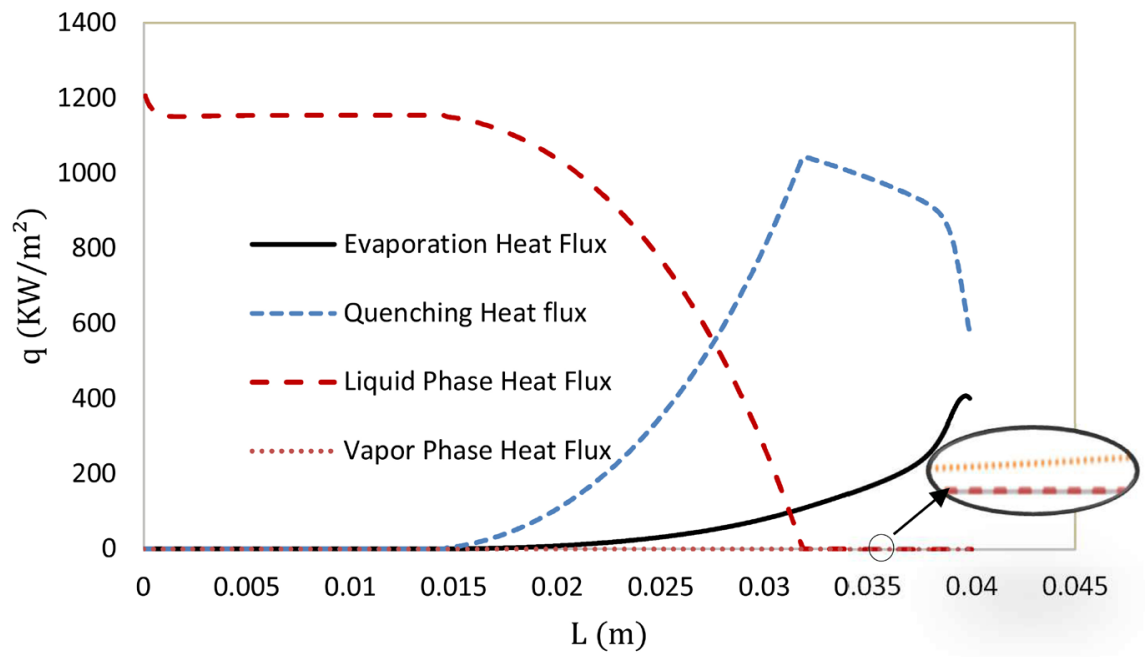

(a)

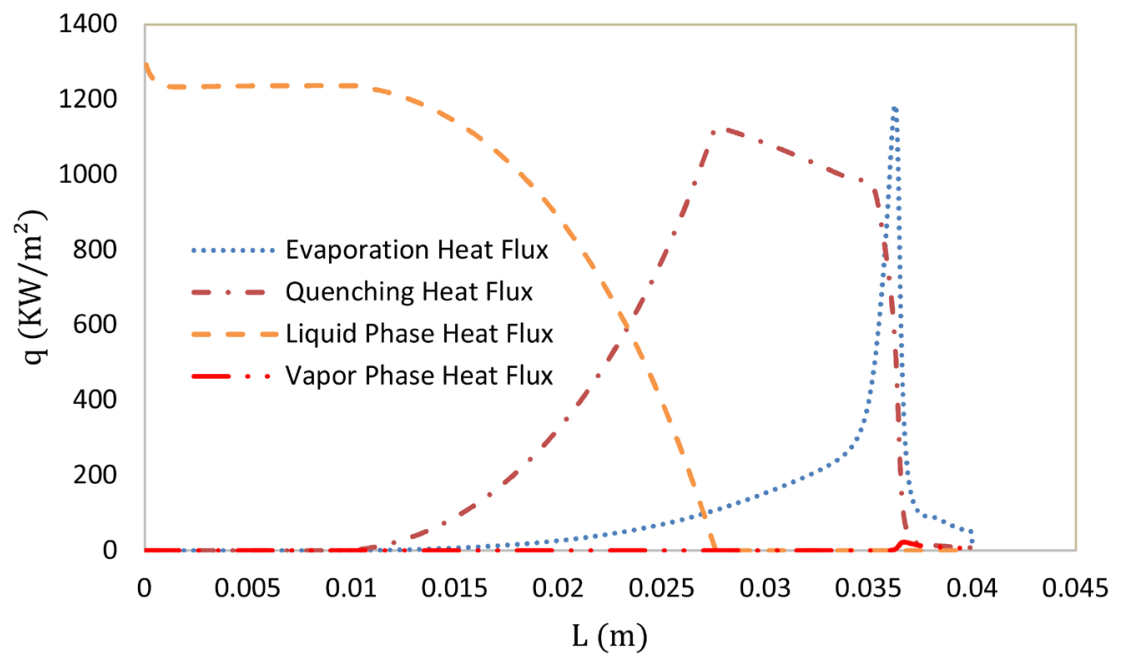

(b)

Figure 8. Wall heat flux partitions in case of (a) $q=700 \mathrm{~kW} \cdot \mathrm{m}^{-2}$ and

(b) $q=750 \mathrm{~kW} \cdot \mathrm{m}^{-2}$. 
Figure 9 represents the vapor volume fraction on the channel wall along the channel at the heat flux range of $650-750 \mathrm{~kW} \cdot \mathrm{m}^{-2}$. Based on this figure, the vapor volume fraction will increase as the heat flux increases. By increasing the heat flux from 600 to $750 \mathrm{~kW} \cdot \mathrm{m}^{-2}$, the vapor volume fraction goes up 188 times. Dry-out occurs in the channel as the value of vapor quality increases causing a sharp drop in the heat transfer coefficients in the channel, which is illustrated in Figure 10 in which the boiling heat transfer and single-phase heat transfer coefficients are presented. At the beginning, there is only a liquid single-phase heat transfer, before the wall reaches to the saturation temperature. As the wall reaches to the saturation temperature, the first nucleate boiling sites are activated and the boiling heat transfer begins. In this part, the bulk fluid temperature is lower than the saturation temperature. The heat transfer coefficient for the liquid phase will decrease as the boiling heat transfer begins. Upon reaching the dry-out area,

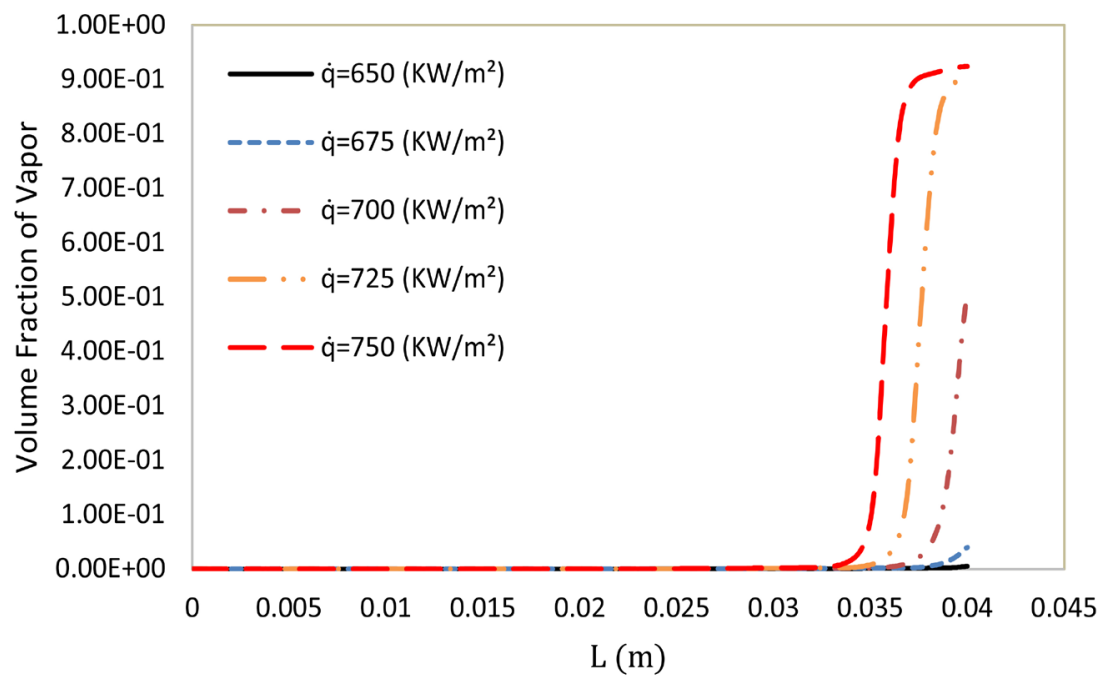

Figure 9. The effect of heat flux on vapor volume fraction along the channel.

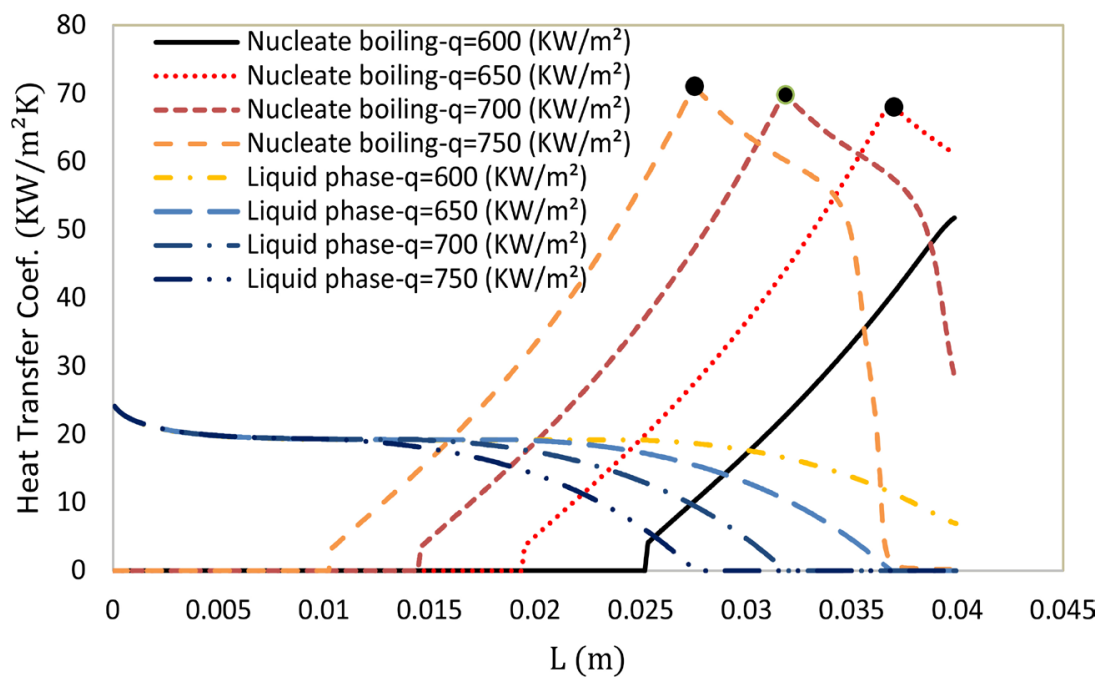

Figure 10. The effect of heat flux on nucleate boiling and liquid single-phase heat transfer coefficient along the channel. 
the boiling heat transfer coefficient decreases significantly as the vapor covers the whole surface of the channel wall. In Figure 10, points where Critical Heat Flux (CHF) occur, is depicted as filled circles, where the heat transfer coefficient reaches its maximum value.

Figure 11 represents the total heat transfer coefficient along the channel with the heat flux of $750 \mathrm{~kW} \cdot \mathrm{m}^{-2}$. According to this figure, there are three distinct regions, single-phase liquid heat transfer, nucleate boiling heat transfer, and the dry-out. This figure illustrates the relationship between these three regions and the related boiling heat transfer coefficient, which is shown in Figure 12 examined by Kim and Mudawar [21]. By comparison between these two Figures (Figure 11 and Figure 12), the different flow regimes are clear. According to Kim and Mudawar, the forced convective heat transfer is dominant in this case. The design of the system to be efficiently and effectively used the mechanism of flow boiling heat transfer in cooling electronic equipment and chips, must be such that the system is working in the nucleate boiling region (close to the CHF point).

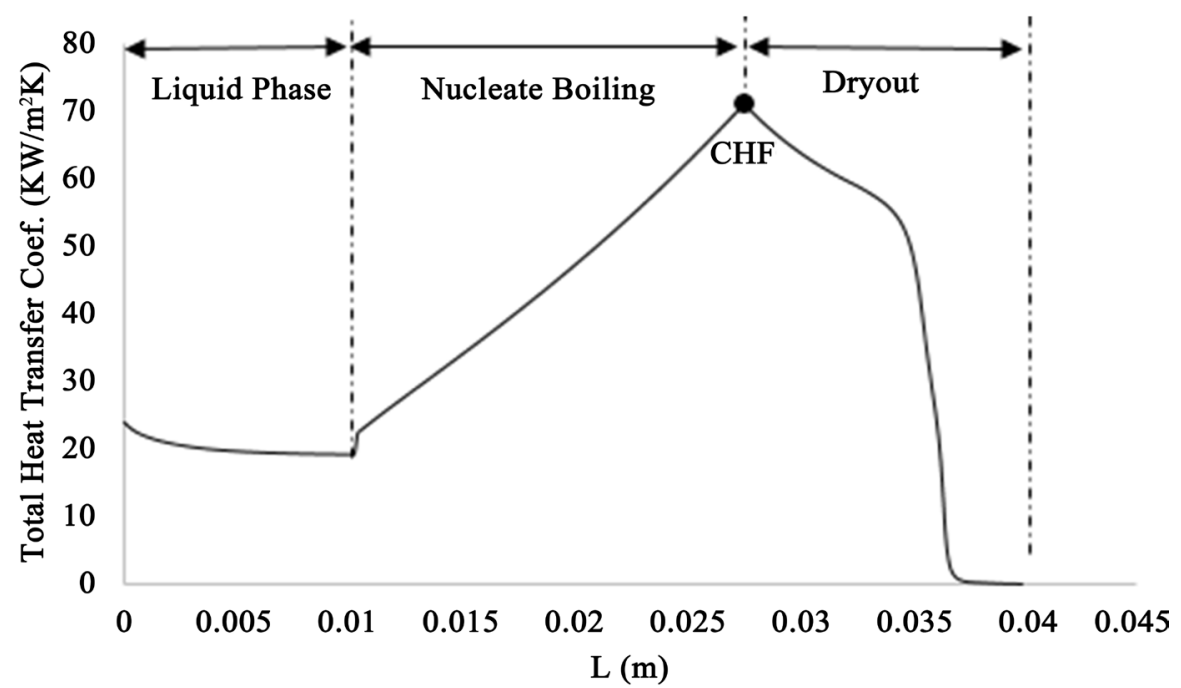

Figure 11. Local heat transfer coefficient along the channel in case of $750 \mathrm{~kW} \cdot \mathrm{m}^{-2}$.

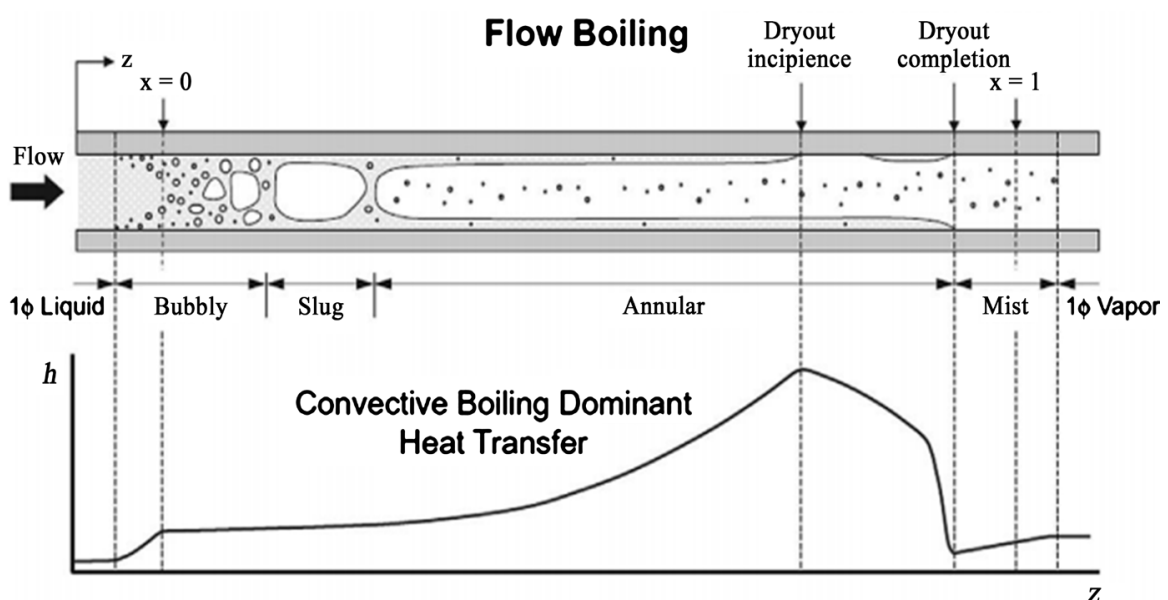

Figure 12. Flow regimes in microchannel [21]. 


\subsection{Effect of Inlet Velocity on Flow Boiling Heat Transfer}

Obviously, the fluid inlet velocity is one of the factors influencing the boilingheat transfer. In this section, the effect of the fluid inlet velocity is reported by changing it from $1-2 \mathrm{~m} \cdot \mathrm{s}^{-1}$. The turbulence in the flow will increase with increasing the fluid inlet velocity which in turn causes the increase of the liquid single-phase heat transfer, while leads to a decrease in the boiling heat transfer as illustrated in Figure 13. Decreasing the boiling heat transfer affect the vapor quality, as illustrated in Figure 14. As can be seen in Figure 14, when inlet velocity increases from 1 to $2 \mathrm{~m} \cdot \mathrm{s}^{-1}$, the vapor quality considerably decreases at the end of the channel.

Figure 15 shows the probability of dry-out occurrence decrease in the channel with increasing the inlet flow velocity. Based on this figure, although the dry-out occurs with the velocity of $1 \mathrm{~m} \cdot \mathrm{s}^{-1}$, it is not observed with increasing the inlet velocity to $1.5 \mathrm{~m} \cdot \mathrm{s}^{-1}$ and $2 \mathrm{~m} \cdot \mathrm{s}^{-1}$. As a result, the flow inlet velocity is one of the important parameters influencing the dry-out, so that the inlet velocity can be used to control the flow and avoid the dry-out condition.

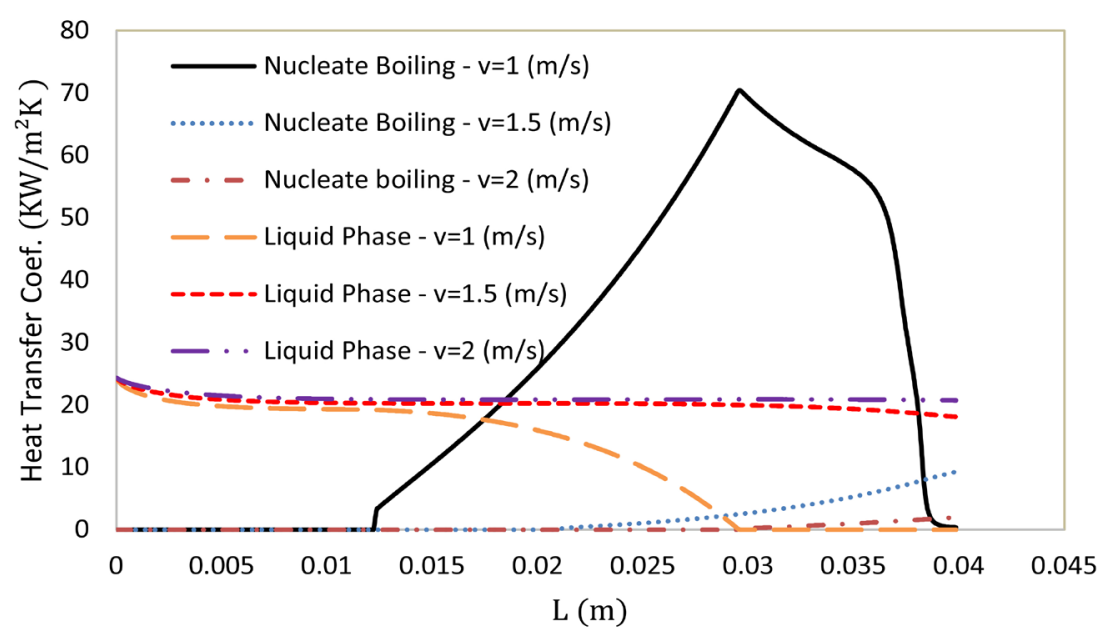

Figure 13. The effect of velocity on nucleate and liquid single-phase heat transfer coefficient along the channel.

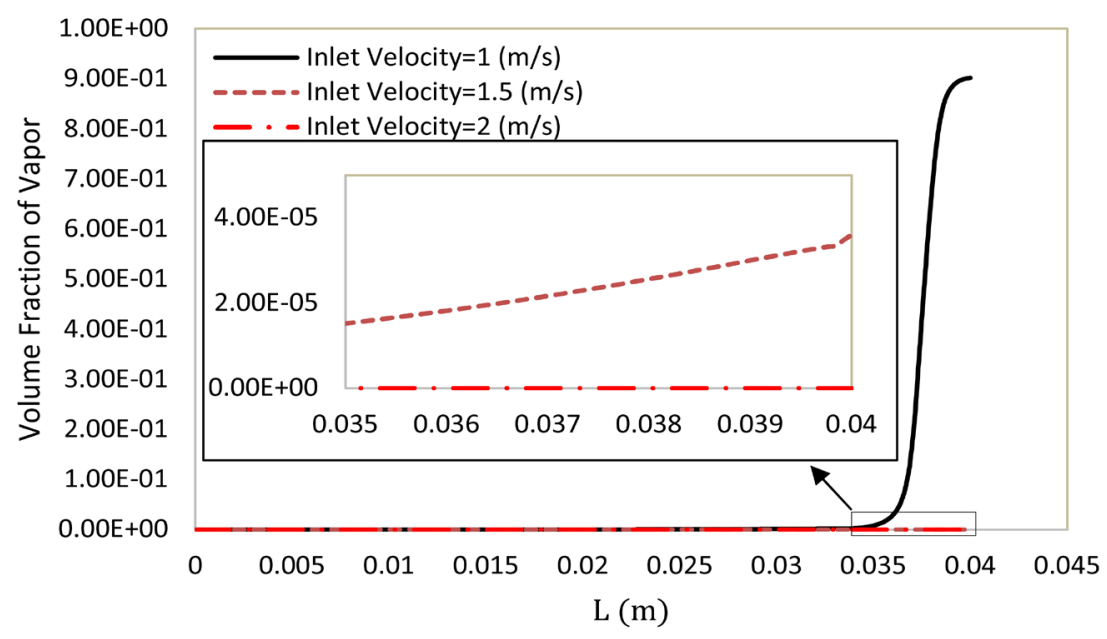

Figure 14. The effect of inlet velocity on volume fraction of vapor along the channel. 


\subsection{Effect of Inlet Subcooled Temperature on Flow Boiling Heat Transfer}

The subcooled temperature is also one of the parameters influencing the boiling heat transfer, the higher the subcooled temperature means the higher temperature differences between inlet and saturation temperature. Thus, the fluid needs more heat to reach the saturation point. Here, the heat flux of $610 \mathrm{~kW} \cdot \mathrm{m}^{-2}$ and inlet velocity of $1 \mathrm{~m} \cdot \mathrm{s}^{-1}$ is considered. In Figure 16 the initial point of boiling shown with filled circles indicating that boiling occurs at a point farther from the channel inlet as subcooled temperature increases. In fact, the single-phase heat transfer increases with increasing subcooled temperature. Figure 17 indicates that in the microchannels, the subcooled temperature may significantly affect the vapor quality, such that decreased subcooled temperature from 69.6-59.6 K leads to an increase vapor quality at the end of the channel from 0.000934 to 0.86 .

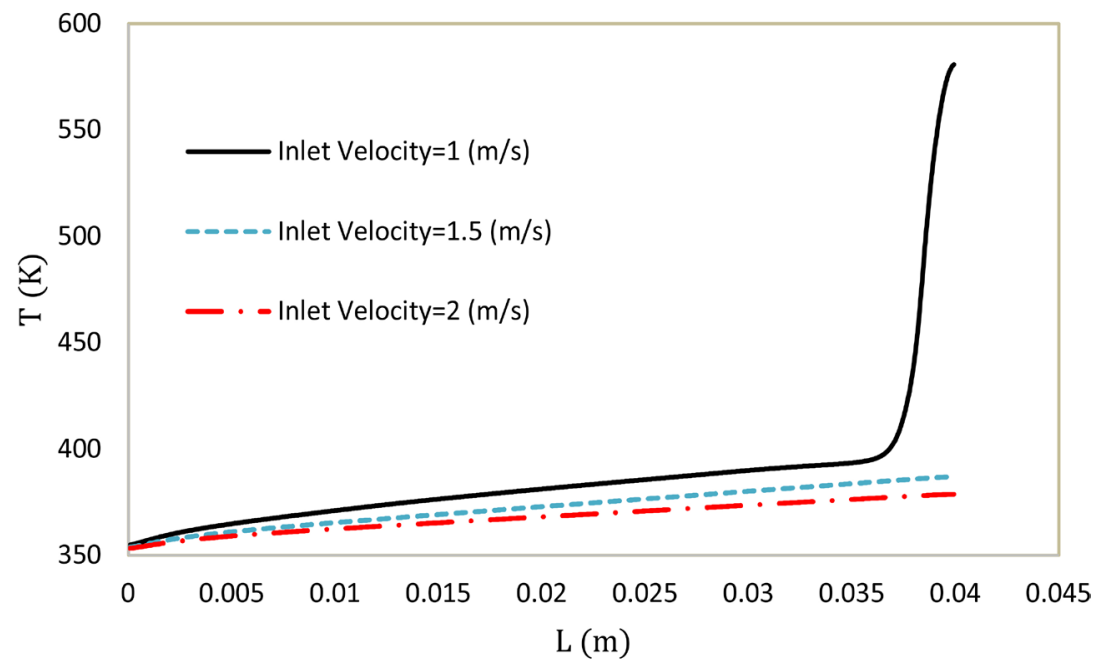

Figure 15. The effect of inlet velocity on inner wall temperature along the channel.

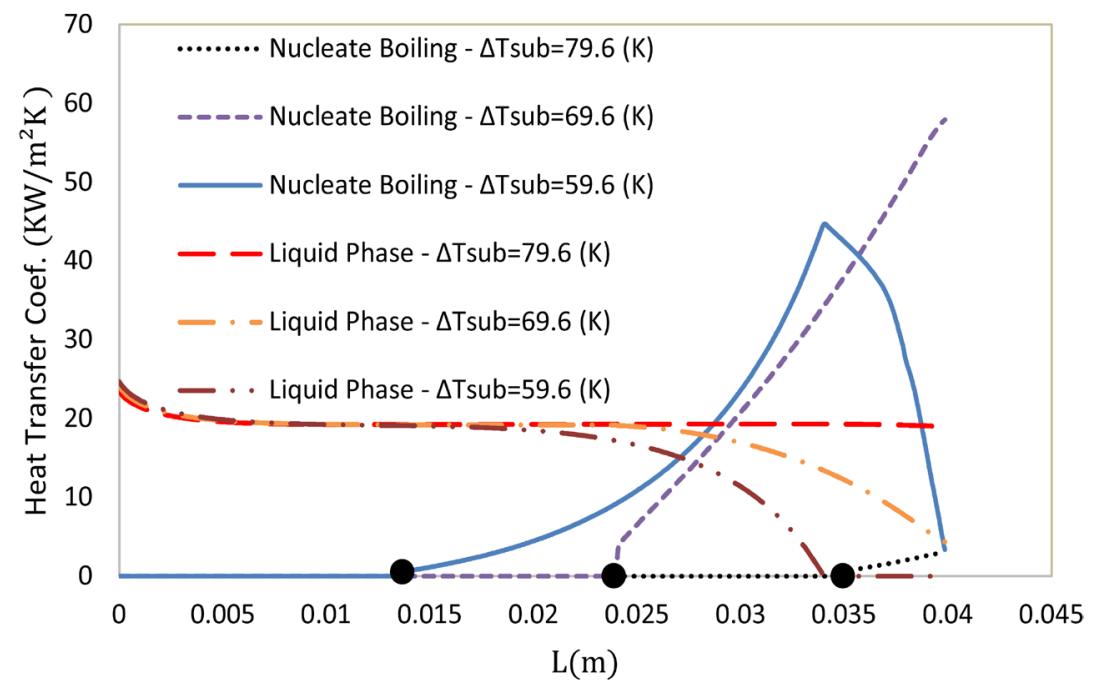

Figure 16. The effect of subcooled temperature on nucleate boiling and liquid single-phase heat transfer coefficient along the channel. 


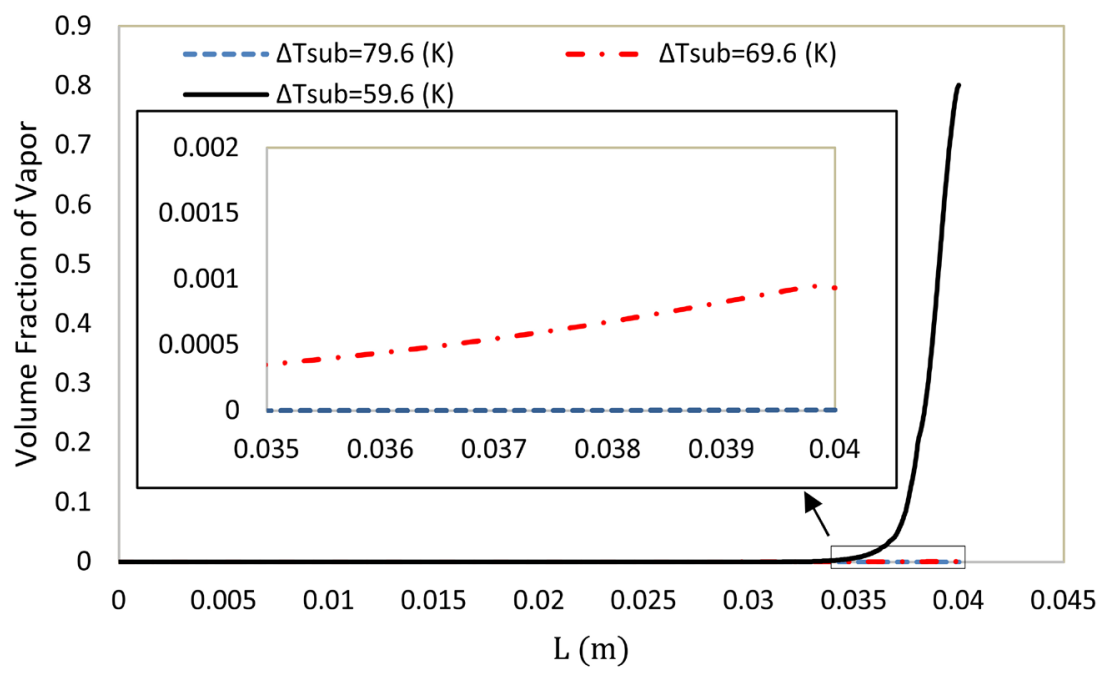

Figure 17. The effect of subcooled temperature on vapor volume fraction along the channel.

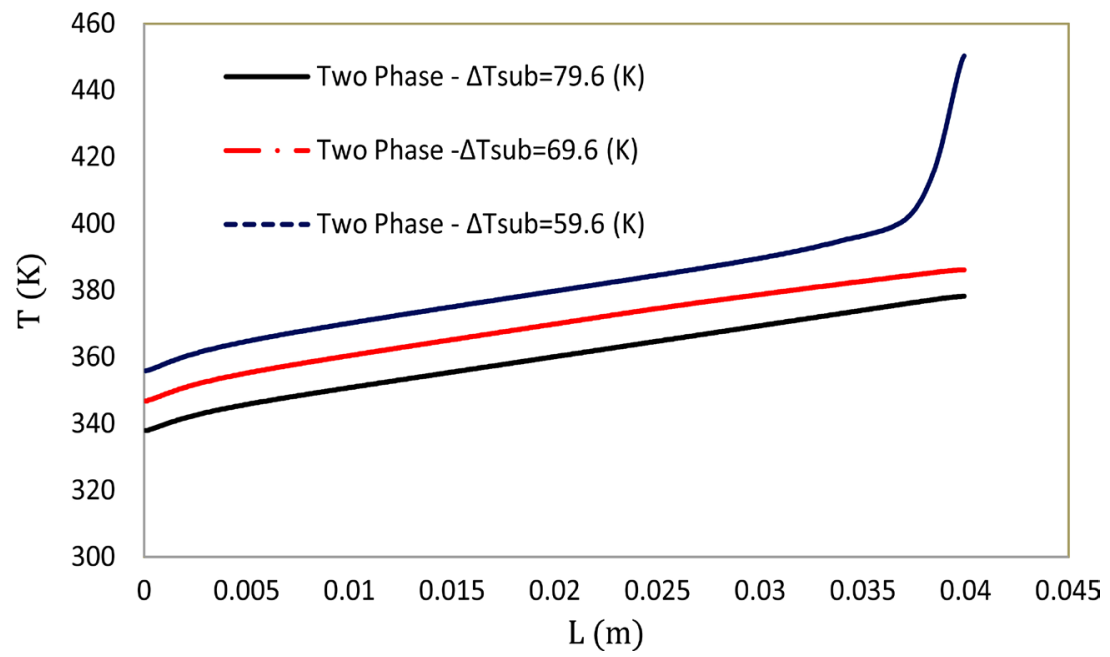

Figure 18. The effect of subcooled temperature on inner wall temperature along the channel.

This means that an excessive increase in the vapor quality causes to create early formation of dry-out region. This would in turn greatly increase the wall temperature (Figure 18) that leads to decrease the effect of flow boiling heat transfer and this is not acceptable for temperature control of the electronic components.

\section{Conclusion}

The present paper demonstrates the forced boiling heat transfer inside a micro-channel with upward flow. Results indicate that in the case of flow boiling, the wall temperature is more uniform and lower than the single-phase flow, which positively influences the service life of the electronic components. When the flow boiling reaches the dry-out point the wall temperature increases significantly and therefore it should be avoided the operating condition to reach the dry-out condition. In order to prevent the dry-out condition from happening, the heat 
flux, inlet velocity, and inlet-subcooled temperatures of the liquid should be carefully controlled. Based on the present results, the probability of dry-out occurrence will increase with increasing the heat flux. Under a high heat flux condition, the dry-out may happen near the channel inlet. The inlet velocity significantly affects the boiling heat transfer and is a key for controlling the dry-out. The dry-out occurs in the case of the inlet velocity of $1 \mathrm{~m} \cdot \mathrm{s}^{-1}$, while it does not occur along the channel with increasing the inlet velocity of $1.5 \mathrm{~m} \cdot \mathrm{s}^{-1}$, and in excess of this velocity. It means that the inlet velocity is one of the most important parameters in the system to prevent dry-out to occur. The subcooled inlet temperature also affects the flow condition and the heat transfer, so that the closer the inlet temperature to the fluid saturation temperature, the higher the probability of dry-out occurrence. Although the application of the flow boiling is recommended for keeping the electronic components working temperature constant and lower value, however, the design conditions should be so that to avoid the dry-out along the channel length. In fact, the system should be designed in such a way that the operating condition be closed in nucleate boiling near the CHF point and region before that.

\section{Conflicts of Interest}

The authors declare no conflicts of interest regarding the publication of this paper.

\section{References}

[1] Falsetti, C., Magnini, M. and Thome, J.R. (2018) Hydrodynamic and Thermal Analysis of a Micro-Pin Fin Evaporator for On-Chip Two-Phase Cooling of High Density Power Micro-Electronics. Applied Thermal Engineering, 130, 1425-1439. https://doi.org/10.1016/j.applthermaleng.2017.10.117

[2] Radwan, A., Ookawara, S., Mori, S. and Ahmed, M. (2018) Uniform Cooling for Concentrator Photovoltaic Cells and Electronic Chips by Forced Convective Boiling in 3D-Printed Monolithic Double-Layer Microchannel Heat Sink. Energy Conversion and Management, 166, 356-371. https://doi.org/10.1016/j.enconman.2018.04.037

[3] Saisorn, S., Kaew-On, J. and Wongwises, S. (2013) An Experimental Investigation of Flow Boiling Heat Transfer of R-134a in Horizontal and Vertical Mini-Channels. Experimental Thermal and Fluid Science, 46, 232-244. https://doi.org/10.1016/j.expthermflusci.2012.12.015

[4] Harirchian, T. and Garimella, S.V. (2009) Effects of Channel Dimension, Heat Flux, and Mass Flux on Flow Boiling Regimes in Microchannels. International Journal of Multiphase Flow, 35, 349-362. https://doi.org/10.1016/j.ijmultiphaseflow.2009.01.003

[5] Ong, C.L. and Thome, J.R. (2009) Flow Boiling Heat Transfer of R134a, R236fa and R245fa in a Horizontal $1.030 \mathrm{~mm}$ Circular Channel. Experimental Thermal and Fluid Science, 33, 651-663. https://doi.org/10.1016/j.expthermflusci.2009.01.002

[6] Owhaib, W., Martın-Callizo, C. and Palm, B. (2004) Evaporative Heat Transfer in Vertical Circular Microchannels. Applied Thermal Engineering, 24, 1241-1253. https://doi.org/10.1016/j.applthermaleng.2003.12.030 
[7] Yu, W., France, D.M., Wambsganss, M.W. and Hull, J.R. (2002) Two-Phase Pressure Drop, Boiling Heat Transfer, and Critical Heat Flux to Water in a Small-Diameter Horizontal Tube. International Journal of Multiphase Flow, 28, 927-941. https://doi.org/10.1016/S0301-9322(02)00019-8

[8] Zhang, L., Koo, J.M., Jiang, L., Asheghi, M., Goodson, K.E., Santiago, J.G. and Kenny, T.W. (2002) Measurements and Modeling of Two-Phase Flow in Microchannels with Nearly Constant Heat Flux Boundary Conditions. Journal of Microelectromechanical Systems, 11, 12-19. https://doi.org/10.1109/84.982858

[9] Hosseini, R., Gholaminejad, A. and Nabil, M. (2011) Concerning the Effect of Surface Material on Nucleate Boiling Heat Transfer of R-113. Journal of Electronics Cooling and Thermal Control, 1, 22-27. https://doi.org/10.4236/jectc.2011.12003

[10] Hosseini, R., Gholaminejad, A. and Jahandar, H. (2011) Roughness Effects on Nucleate Pool Boiling of R-113 on Horizontal Circular Copper Surfaces. World Academy of Science, Engineering and Technology, 55, 679-684.

[11] Li, H., Vasquez, S.A., Punekar, H. and Muralikrishnan, R. (2011) Prediction of Boiling and Critical Heat Flux Using an Eulerian Multiphase Boiling Model. In: ASME 2011 International Mechanical Engineering Congress and Exposition, American Society of Mechanical Engineers Digital Collection, 463-476. https://doi.org/10.1115/IMECE2011-65539

[12] Fluent, A.N.S.Y.S. 16.2: Fluent Theory Guide. ANSYS Help Viewer.

[13] Kurul, N. and Podowski, M.Z. (1991) On the Modeling of Multidimensional Effects in Boiling Channels. Proceedings of 27 th National Heat Transfer Conference, Minneapolis, 28-31 July 1991, 30-40.

[14] Del Valle, V.H. and Kenning, D.B.R. (1985) Subcooled Flow Boiling at High Heat Flux. International Journal of Heat and Mass Transfer, 28, 1907-1920. https://doi.org/10.1016/0017-9310(85)90213-3

[15] Cole, R. (1960) A Photographic Study of Pool Boiling in the Region of the Critical Heat Flux. AIChE Journal, 6, 533-538. https://doi.org/10.1002/aic.690060405

[16] Tolubinsky, V.I. and Kostanchuk, D.M. (1970) Vapour Bubbles Growth Rate and Heat Transfer Intensity at Subcooled Water Boiling. In: International Heat Transfer Conference, Begel House Inc., Danbury, 1-11. https://doi.org/10.1615/IHTC4.250

[17] Lemmert, M. and Chawla, J.M. (1977) Influence of Flow Velocity on Surface Boiling Heat Transfer Coefficient. In: Hahne, E. and Grigull, U., Eds., Heat Transfer in Boiling, Academic Press and Hemisphere, New York, 237-247.

[18] Kocamustafaogullari, G. and Ishii, M. (1995) Foundation of the Interfacial Area Transport Equation and Its Closure Relations. International Journal of Heat and Mass Transfer, 38, 481-493. https://doi.org/10.1016/0017-9310(94)00183-V

[19] Ioilev, A., Samigulin, M., Ustinenko, V., Kucherova, P., Tentner, A., Lo, S. and Splawski, A. (2007) Advances in the Modeling of Cladding Heat Transfer and Critical Heat Flux in Boiling Water Reactor Fuel Assemblies. 12 th International Topical Meeting on Nuclear Reactor Thermal Hydraulics, Pittsburgh, September 2007, 47.

[20] https://www.peacesoftware.de/einigewerte/wasser_dampf_e.html

[21] Kim, S.M. and Mudawar, I. (2014) Review of Databases and Predictive Methods for Heat Transfer in Condensing and Boiling Mini/Micro-Channel Flows. International Journal of Heat and Mass Transfer, 77, 627-652.

https://doi.org/10.1016/j.ijheatmasstransfer.2014.05.036 